\title{
A graphite thermal evaporation source for aluminum
}

Y. A. Folz, J. S. Hickmann, L. F. M. Braun, and R. E. Francke

Citation: Journal of Vacuum Science \& Technology A 8, 151 (1990); doi: 10.1116/1.577052

View online: https://doi.org/10.1116/1.577052

View Table of Contents: https://avs.scitation.org/toc/jva/8/1

Published by the American Vacuum Society

\section{ARTICLES YOU MAY BE INTERESTED IN}

Vacuum thermal evaporation of polyaniline doped with camphor sulfonic acid Journal of Vacuum Science \& Technology A 33, 031510 (2015); https://doi.org/10.1116/1.4916990

Transport of bromine out from a graphite molecular beam source: A case of bulk diffusion Journal of Applied Physics 57, 1102 (1985); https://doi.org/10.1063/1.335472

Supersonic atomic and molecular halogen nozzle beam source

Review of Scientific Instruments 48, 58 (1977); https://doi.org/10.1063/1.1134850

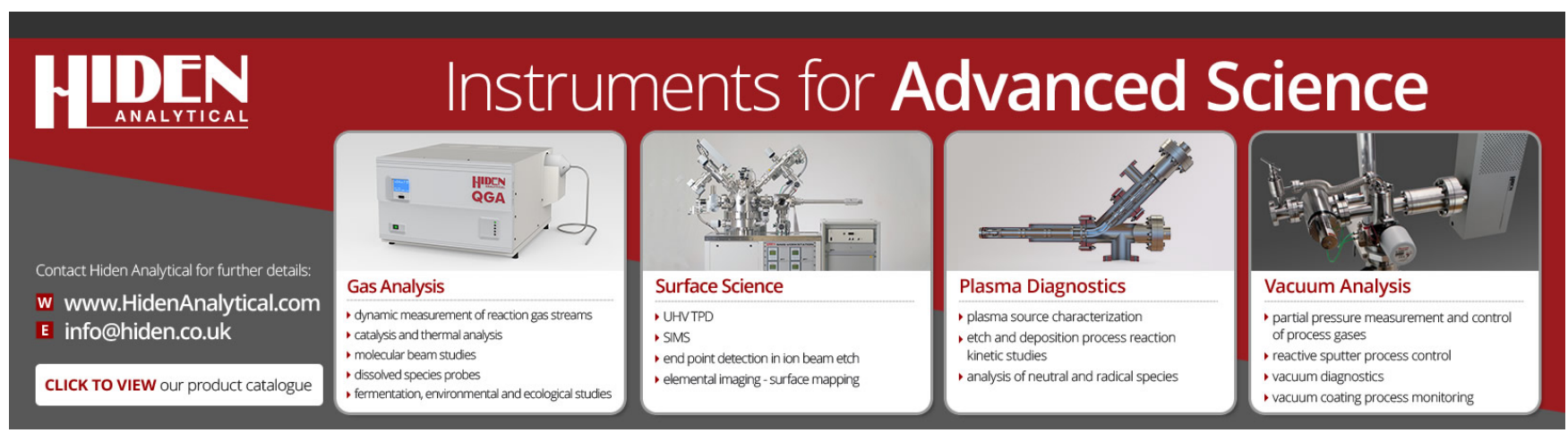


cooled during film deposition monitoring. Because of such low operation temperatures, contamination resulting from outgassing of the photoresist is likely negligible.

In conclusion, substantial saving on quartz thickness sensor crystals can be made by using a thin buffer layer of photoresist. Any additional coating on the buffered sensor can be washed away by acetone. Therefore, the crystal can be reused many times.

a) Author to whom correspondence should be addressed.

${ }^{1}$ Recoating service is provided by Lebow Company, Goleta, California 93117.

${ }^{2}$ Photoresist AZ-1300-31 from Shipley Company Inc., Newton, MA 02162.

${ }^{3}$ Standard quartz thickness sensor from Inficon, Leybold-Heraeus Inc., San Jose, California 95131.

\title{
A graphite thermal evaporation source for aluminum
}

\author{
Y. A. Folz, J. S. Hickmann, L. F. M. Braun, and R. E. Francke \\ Instituto de Física da UFR GS, Caixa Postal 15051, CEP 91500 Porto Alegre, Brasil
}

(Received 14 April 1989; accepted 22 July 1989)

\begin{abstract}
Aluminum films are widely used in optics, electronics and other industrial applications as a result of its excellent reflectivity, simplicity to make high purity films and good adherence to several important technological materials. The most common technique to produce Al films is by thermal evaporation of the metal from an appropriate heat source in high vacuum. Much effort has been devoted to produce a reliable evaporation source since liquid $\mathrm{Al}$ dissolves all metals and reacts with refractory oxides generating impure films. ${ }^{1}$ The most common evaporation source is a resistance heated coiled tungsten filament. ${ }^{2}$ Under careful conditions ${ }^{3}$ this source generates extremely pure films. However, $\mathrm{Al}$ dissolves tungsten, generating $\mathrm{Al}_{4} \mathrm{~W}$ and thinning the filament, thus decreasing severely the lifetime of this source. Thus, a tungsten source can be used very few times and in certain cases it is difficult to replace. Al can also be evaporated from an electron beam source. ${ }^{4}$ Other specialized evaporation sources have also been described in the literature. ${ }^{5,6}$
\end{abstract}

In this work, a resistance heated graphite evaporation source for $\mathrm{Al}$ is described. This source is made from a high purity cylindrical graphite rod with a $\frac{5}{16}$ in. diameter and $2 \frac{1}{4}$ in. long. The central part of the rod is thinned so that its cross section becomes about $0.5-0.7$ that of the original rod. This is easily done using No. 120 sand paper. Four blind holes are drilled in the thinned portion of the graphite rod as shown in Fig. 1. Each end of the graphite source is pressed between two massive copper blocks ( $A$ in Fig. 1) which in turn are bolted to copper electrodes (B). This procedure to hold the graphite provides a large area for electrical contact and thermal dissipation.
The graphite source is baked out before being used. Our procedure is to apply a power higher than that used in working conditions until the evaporation of the adsorbed gases ceased. In order to use the graphite source, $\mathrm{Al}$ is loaded in the two central blind holes described above. The lateral holes help to confine the heat. After that enough power is applied to the source so as to melt the $\mathrm{Al}$. This power is usually about $1 \mathrm{~kW}$ at $200 \mathrm{~A}$. When this is accomplished a slight increase of the applied power insured a deposition rate of about $4 \mathrm{~nm} / \mathrm{s}$ over a substrate at about $30 \mathrm{~cm}$ from the source.

Aluminum reacts with graphite producing $\mathrm{Al}_{4} \mathrm{C}_{3}$, thinning the source and eventually destroying it. However, this filament is much thicker than the tungsten one, thus, its lifetime is much longer. Furthermore the vapor pressure of $\mathrm{Al}_{4} \mathrm{C}_{3}$ is much lower than that of $\mathrm{Al}$ so that high purity thick films can also be generated as from a tungsten source. Ocassionally the appearance of a yellow deposit over the aluminum thin film was observed. This is attributed to $\mathrm{Al}_{4} \mathrm{C}_{3}$ be-

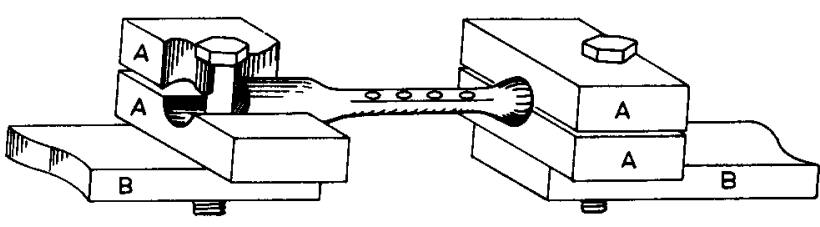

FIG. 1. The graphite evaporation source mounted on the electrodes. 
cause it appeared whenever the source developed a spot with a very high temperature. It has been reported that a graphite aluminum evaporation source disintegrates after a short period (a week) of use. ${ }^{7}$ We have used our source for over 30 evaporation cycles and they have lasted for months. However, we did observe that if the source is left in air it disintegrates. Thus, desintegration ${ }^{7}$ is more likely a room temperature reaction involving $\mathrm{Al}_{4} \mathrm{C}_{3}$ with water. The long source duration is achieved by keeping them in vacuum most of the time.

Finally the quality of the film was measured through its reflectivity using a Strong-type reflectometer ${ }^{3}$ with a $337 \mathrm{~nm}$ nitrogen laser. It was found that the reflection coefficient at $45^{\circ}$ and $s$ polarization was $94 \pm 1 \%$ using our evaporation source or a tungsten filament. This result compares favorably to a theoretical value of $94.6 \% .^{4}$
In conclusion we have developed a long lifetime Al evaporation source which produces high quality films.

The financial support of PROPESP, CNPq, FINEP, and FAPERGS is greatly appreciated.

'P. S. Kislyi, M. A. Kuzenkova, L. I. Struk, and M. S. Borovikova, High Temp. High Pressures 10, 305 (1978).

${ }^{2}$ L. Holland, Vacuum Deposition of Thin Films (Chapman and Hall, London, 1958), p. 169.

${ }^{3}$ G. Hass, J. B. Heaney, and W. R. Hunter, in Physics of Thin Films, edited by G. Hass, M. H. Francombe, and J. L. Vossen (Academic, New York, 1982), Vol. 12, pp. 1-51.

${ }^{4}$ G. J. Graper, J. Vac. Sci. Technol. 9, 33 (1972).

${ }^{5}$ P. A. B. Toombs and A. J. Jeal, J. Sci. Instrum. 42, 722 (1965).

${ }^{6} \mathrm{~J}$. L. Breunig, Rev. Sci. Instrum. 42, 1259 (1971).

${ }^{7}$ S. Tabata, M. Iwata, and T. Sawaki, Vacuum 7/8, 88 (1959). 